\section{Preditores de soropositividade para HIV em indivíduos não abusadores de drogas que buscam centros de testagem e aconselhamento de Porto Alegre, Rio Grande do Sul, Brasil}

\author{
Predictors of HIV seropositive status \\ in non-IV drug users at testing and counseling \\ centers in Porto Alegre, Rio Grande do Sul, Brazil
}

Flávio Pechansky 1

Lisia von Diemen 1

Félix Kessler 1

Raquel De Boni 1

Hilary Surrat 2

James Inciardi 2

\footnotetext{
1 Centro de Pesquisa em Álcool e Drogas, Universidade Federal do Rio Grande do Sul, Porto Alegre, Brasil.

2 Center for Drug and Alcohol Studies, University of Delaware, Newark, U.S.A

Correspondência F. Pechansky Centro de Pesquisa em Álcool e Drogas, Universidade Federal do Rio Grande do Sul. Rua Itaqui 99, sala 502, Porto Alegre, RS 90460-140, Brasil. fpechans@uol.com.br
}

\begin{abstract}
This study describes HIV-related behaviors recorded through a questionnaire applied to 570 individuals in Porto Alegre, Rio Grande do Sul, Brazil, who were not regular drug users. Mean age was 30.3 years, $51.1 \%$ were male, and most were low-income (59.1\%). The HIV seropositive rate was $9.9 \%$ (13.1\% for males, $6.9 \%$ for females), and there was a positive association with male gender, age over 30 years, and low income. Women reported more unprotected sex (86.4\%) than men (74.4\%) and more sex involving drugs (11.6\% vs. 2.1\%); men reported more unprotected homosexual sex (18.7\% vs. 1.4\%) and more sex with sex workers (19.0\% vs. $0.4 \%$ ). There was no association between sporadic drug use and seropositive status. The association between age and seropositive status confirms previous findings, indicating more lifetime risk exposure. The study confirms the so-called pauperization of the epidemic, with poor individuals showing a higher seropositive rate. Males and females showed different behaviors associated with seropositive status, confirming the need for specific and differentiated preventive strategies for each group.
\end{abstract}

Acquired Immunodeficiency Syndrome; Drug Abuse; Risk Behavior; Serologic Tests

\section{Introdução}

A Síndrome de Imunodeficiência Humana Adquirida (AIDS) tornou-se um dos mais graves problemas da saúde pública das últimas décadas. O Ministério da Saúde do Brasil registrava, até setembro de 2003, mais de 270 mil casos de AIDS relatados desde o início da epidemia, em 1980, com uma incidência média global de 9,8/ 100 mil habitantes/ano. As maiores concentrações de casos de AIDS ocorrem nas regiões Sudeste e Sul do país, com $84,0 \%$ dos casos notificados. As maiores taxas de incidência estão nos Estados de São Paulo, Rio de Janeiro e Rio Grande do Sul - que, em 2002, registrou uma incidência de 25,6 casos novos para cada $100 \mathrm{mil}$ habitantes, a mais alta do país naquele ano 1 . Essas taxas se devem principalmente ao aumento da transmissão heterossexual nos últimos anos, o que vem sustentando as altas taxas da epidemia, principalmente entre as mulheres. Ao mesmo tempo, tem havido uma tendência à redução na taxa de incidência por transmissão homossexual, que se encontrava acima de $30,0 \%$ na primeira década da epidemia e hoje está diminuída pela metade (aproximadamente 15,8/100 mil) 2,3.

Além do aumento da transmissão heterossexual, percebe-se, ao longo dos anos, uma maior prevalência de soropositividade para HIV nas parcelas da população que apresentam menor escolaridade e renda 4 . Torna-se relevante res- 
saltar esse fato, pois, segundo o modelo teórico de risco proposto pelo nosso grupo de pesquisa 5, essas e outras variáveis são modificáveis mesmo que dificilmente - e assim passíveis de intervenção direta.

Os autores têm estudado a relação entre HIV e uso de drogas no Sul do Brasil e têm demonstrado que os consumidores de drogas apresentam alta prevalência de infecção por HIV $(22,5 \%)$, e os principais comportamentos associados à soropositividade são a relação sexual desprotegida e o uso de drogas injetáveis 6 , o que está de acordo com a literatura internacional 7 . O potencial viés gerado por tais estudos é o de desconsiderar que a transmissão do vírus pode ocorrer também de forma significativa em usuários não sistemáticos de drogas, uma vez que não é necessário que o indivíduo seja dependente para que ele tenha uma perda do controle do uso da substância, com conseqüente perda da crítica quanto a práticas de risco, dentre elas, a prevenção de doenças sexualmente transmissíveis 8 .

A busca pelo teste HIV varia de acordo com o tipo de população estudada. Por exemplo, mulheres que têm mais comportamentos de risco para HIV costumam fazer mais testes e voltar para receber o resultado. Da mesma forma, indivíduos que usam drogas injetáveis ou que tiveram recentemente quatro ou mais parceiros também tendem a realizar mais testes 9,10.

Outra população que tem a percepção de risco aumentada é a dos homens que fazem sexo com homens, que relatam procurar o teste HIV para motivarem-se a mudar os cuidados com a sua saúde, conhecer e definir condições médicas existentes e para aliviar a dúvida sobre o seu estado sorológico. Em contrapartida, afirmam que não se testam para evitar o impacto psicológico de um resultado positivo e a discriminação social ligada à doença 11,12.

Levando-se em consideração as diferenças existentes nos diferentes subgrupos acima mencionados, torna-se necessário também conhecer a expressão da preocupação com o risco de soropositividade nos indivíduos que se percebem sob risco, mas não estariam naturalmente encaixados em categorias "de risco evidente”, como, por exemplo, os usuários eventuais de substâncias psicoativas. Dessa forma, o objetivo deste estudo é descrever as características demográficas e os comportamentos associados à soropositividade por HIV em indivíduos que buscavam testagem sorológica em dois centros de testagem e aconselhamento de
Porto Alegre e que ou não faziam uso de drogas ou o faziam de forma não sistemática, visando a um melhor entendimento das características atuais da epidemia, a fim de promover estratégias mais eficazes de prevenção.

\section{Método}

\section{Sujeitos e delineamento}

Foi realizado um estudo transversal com uma amostra de conveniência obtida de dois grandes centros de testagem e aconselhamento (CTAs) da prefeitura de Porto Alegre e do governo do Estado do Rio Grande do Sul, durante aproximadamente vinte meses, entre 1995 e 1997. No centro municipal, os clientes responderam à pesquisa após o aconselhamento pós-teste HIV e, no centro estadual, após o aconselhamento pré-teste.

\section{Critérios de inclusão e coleta de dados}

Os 570 sujeitos deste estudo são provenientes do processo amostral de um estudo de natureza similar, que visava conhecer os comportamentos e situações associadas a maior soropositividade de usuários de droga sistemáticos que estivessem fazendo uso regular de drogas no mês prévio à coleta de dados $13,14,15,16,17$. O uso regular foi definido como ter utilizado substâncias psicoativas quase sempre ou todos os dias no mês prévio à coleta, o que era aferido pelo questionário sobre comportamentos de risco para AIDS. O presente estudo analisa os dados dos sujeitos que relataram não uso ou uso por poucas vezes no último mês de qualquer subs tância psicoativa. Foram excluídos os indivíduos que haviam injetado drogas alguma vez nos 30 dias prévios à coleta e 24 indivíduos cujo resultado do teste anti-HIV não foi obtido. Foram treinados 15 estudantes de Psicologia ou Medicina para a coleta dos dados.

As amostras de sangue foram testadas para anticorpos anti-HIV sob formato padrão, usando o método ELISA, nos laboratórios dos próprios CTAs.

\section{Instrumento}

O instrumento utilizado para avaliação dos comportamentos nos usuários de drogas foi a versão brasileira do questionário comportamento de risco para AIDS 18, que é a tradução 
adaptada do Risk Assessment Battery: Validity and Reliability (Metzger DE; 1993, comunicação pessoal). O instrumento é de fácil entendimento, tendo sido auto-administrado, na maioria dos casos, em um tempo médio de 10 minutos. As questões do comportamento de risco para AIDS versam sobre dados demográficos, história de uso de drogas, estado sorológico para o HIV, comportamento sexual, relações envolvendo sexo, dinheiro e drogas e preocupações referentes à infecção e transmissão do vírus.

\section{Aspectos éticos}

O ingresso dos sujeitos neste estudo ocorreu após consentimento verbal, em função da preservação do anonimato, necessária ao atendimento nos CTAs. O projeto foi aprovado pelo Conselho Estadual de Entorpecentes e pela Comissão de Ética e Pesquisa do Hospital de Clínicas de Porto Alegre, tendo sido aprovado pelas devidas chefias dos referidos centros.

\section{Análise dos dados}

Os dados foram inseridos em uma base em SPSS 11.0 e agrupados por categorias. Foram submetidos à análise exploratória usando o teste do qui-quadrado, com nível de significância de 5,0\%, sendo apresentados em tabelas de contingência e em razões de chance. Quando apropriado, optou-se por estratificar alguns achados por gênero.

\section{Resultados}

A soropositividade geral foi de $9,9 \%$, sendo $13,1 \%$ entre os homens e $6,9 \%$ entre as mulheres. A Tabela 1 mostra os principais achados demográficos da amostra estudada e sua relação com soropositividade HIV. Os 570 sujeitos dessa amostra apresentaram idade que variava entre 14 e 84 anos, com média de 30,3 anos (DP = $11,7)$, e a distribuição por gênero foi $51,1 \%$ de homens e 48,9\% de mulheres. Com relação à escolaridade e à renda, $38,7 \%$ completaram o segundo grau, e 59,1\% ganhavam até três salários mínimos. Além disso, 42,8\% eram casados, e $63,7 \%$ tinham trabalho regular. Na análise bivariada, foi associado com soropositividade: ser homem, ter mais de trinta anos e ter renda inferior a três salários mínimos.

A Tabela 2 mostra a porcentagem de respostas afirmativas para cada comportamento isolado segundo o gênero. Observa-se que a variável de maior prevalência foi a relação heterossexual desprotegida, em ambos os sexos, ten- do sido significativamente maior entre as mulheres; também foi mais prevalente entre as mulheres ter tido relação sexual com usuário de droga injetável. Foi significativamente superior entre os homens ter relações homossexuais sem proteção e relações com profissio nais de sexo.

A Tabela 3 descreve os comportamentos associados à soropositividade. Esteve associado com soropositividade ter tido relação homos sexual desprotegida, ter tido relação sexual com profissional de sexo e ter usado droga injetável alguma vez desde 1980.

O uso de substâncias psicoativas nos 30 dias prévios à entrevista está explicitado na Tabela 4 . Observou-se que 9,3\% dos respondentes tinham usado algum tipo de droga ilícita nos trinta dias prévios à coleta de dados. No que compete ao uso das substâncias psicoativas mais comuns, o uso de maconha foi relatado por 7,0\% dos indivíduos, de álcool $66,3 \%$, de calmantes $9,3 \%$ e de cocaína $3,9 \%$. Não foi encontrada associação entre o uso eventual dessas drogas e soropositividade. Encontrou-se uma associação negativa entre consumo de álcool e soropositividade.

\section{Discussão}

Alguns achados sócio-demográficos deste es tudo devem ser levados em consideração. É importante ressaltar que essa amostra é proveniente de um estrato sócio-econômico e cultural pouco favorecido. Sabe-se também que pessoas que procuram testagem sorológica se consideram sob maior risco de adquirir/transmitir HIV ou estiveram expostas a situações de risco, o que restringe, em parte, a generalização dos dados 19,20,21,22. Apesar de não representar do ponto de vista estatístico a população de Porto Alegre, a amostra em algum grau espelha estas características: os CTAs são dois grandes centros de testagem localizados no município de Porto Alegre e drenam milhares de casos todos os anos para essa avaliação. Dessa forma, os dados aqui encontrados têm alguma representatividade e definem características específicas da amostra estudada.

No que compete ao comportamento de buscar testagem HIV, que caracteriza a inclusão dos sujeitos neste estudo, há vários elementos significativos a serem considerados, como, por exemplo, a percepção de exposição a risco por estar envolvido com múltiplos parceiros sexuais, ou por formas específicas de relacionamento sexual. Os motivos que levam os indivíduos a buscar um teste para HIV são bastante 
Variáveis demográficas e relação com soropositividade para HIV.

\begin{tabular}{|c|c|c|c|c|c|c|}
\hline \multirow[t]{2}{*}{ Variável } & \multicolumn{2}{|c|}{ Geral $(n=570)^{\star}$} & \multicolumn{2}{|c|}{$\mathrm{HIV}+(\mathrm{n}=59)^{\star}$} & \multirow{2}{*}{$\begin{array}{c}\mathrm{RC}^{\star \star}(\mathrm{IC} 95 \%) \\
\mathrm{n}=511\end{array}$} & \multirow[t]{2}{*}{$p^{\star \star \star}$} \\
\hline & $n$ & $\%$ & $n$ & $\%$ & & \\
\hline \multicolumn{7}{|l|}{ Gênero } \\
\hline Feminino & 277 & 48,9 & 19 & 6,9 & 1 & $<0,05$ \\
\hline Masculino & 289 & 51,1 & 38 & 13,1 & $2,06(1,16-3,66)$ & \\
\hline \multicolumn{7}{|l|}{ Idade (anos) } \\
\hline$<20$ & 90 & 16,4 & 4 & 4,4 & 1 & $<0,05$ \\
\hline $20-30$ & 213 & 38,9 & 18 & 8,5 & $1,98(0,61-7,16)$ & \\
\hline$>30$ & 245 & 44,7 & 33 & 13,5 & $3,35(1,09-11,50)$ & \\
\hline \multicolumn{7}{|l|}{ Escolaridade } \\
\hline Até 1ㅇ grau incompleto & 223 & 39,2 & 17 & 7,6 & $0,71(0,35-1,43)$ & 0,14 \\
\hline 1ㅇ grau completo/2o incompleto & 126 & 22,1 & 18 & 14,3 & $1,43(0,70-2,90)$ & \\
\hline 2o grau completo ou mais & 220 & 38,7 & 23 & 10,5 & 1 & \\
\hline \multicolumn{7}{|l|}{ Renda (salário mínimo) } \\
\hline Até 1 & 117 & 21,2 & 15 & 12,8 & $2,40(1,03-5,59)$ & 0,05 \\
\hline $1-3$ & 209 & 37,9 & 28 & 13,4 & $2,52(1,21-5,31)$ & \\
\hline 4 ou + & 225 & 40,8 & 13 & 5,8 & 1 & \\
\hline \multicolumn{7}{|l|}{ Situação conjugal } \\
\hline Solteiro/outro & 324 & 57,2 & 29 & 12,0 & $0,72(0,41-1,29)$ & 0,51 \\
\hline Casado & 242 & 42,8 & 29 & 9,0 & 1 & \\
\hline \multicolumn{7}{|l|}{ Situação profissional } \\
\hline Trabalho regular & 358 & 63,7 & 42 & 11,7 & 1 & \\
\hline Trabalho irregular & 204 & 36,3 & 15 & 7,4 & $1,68(0,91-3,10)$ & 0,01 \\
\hline
\end{tabular}

* A soma dos n para algumas variáveis não representa o número total de casos devido a perdas de informação na coleta dos dados.

** Razão de chances: refere-se à comparação entre indivíduos HIV positivos e HIV negativos.

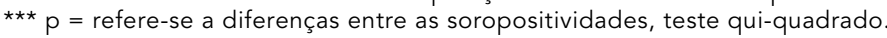

Tabela 2

Exposição a situações de risco para HIV alguma vez desde 1980, estratificado por gênero.

\begin{tabular}{|c|c|c|c|c|c|c|}
\hline \multirow[t]{3}{*}{ Situação de risco } & \multicolumn{4}{|c|}{ Gênero } & \multirow[t]{3}{*}{$\mathrm{RC}^{\star}(\mathrm{IC} 95 \%)$} & \multirow[t]{3}{*}{$\mathrm{p}$} \\
\hline & \multicolumn{2}{|c|}{ Homens $(n=289)$} & \multicolumn{2}{|c|}{ Mulheres $(n=277)$} & & \\
\hline & $\mathrm{n}$ & $\%$ & $\mathrm{n}$ & $\%$ & & \\
\hline Transfusão sangüínea & 15 & 5,2 & 14 & 5,1 & $1,0(0,5-2,2)$ & 1,000 \\
\hline Relação heterossexual sem preservativo & 215 & 74,4 & 240 & 86,6 & $0,5(0,3-0,6)$ & $<0,001$ \\
\hline Relação homossexual sem preservativo & 54 & 18,7 & 4 & 1,4 & $13,1(4,5-43,2)$ & $<0,001$ \\
\hline Relação sexual com profissional de sexo & 55 & 19,0 & 1 & 0,4 & $64,9(8,9-472,3)$ & $<0,001$ \\
\hline Relação sexual por dinheiro & 9 & 3,1 & 19 & 6,9 & $0,4(0,2-0,98)$ & 0,052 \\
\hline Uso de drogas injetáveis & 10 & 3,5 & 3 & 1,1 & $3,3(0,9-12,0)$ & 0,090 \\
\hline Parceiro de usuário de drogas injetáveis & 6 & 2,1 & 32 & 11,6 & $0,2(0,1-0,4)$ & $<0,001$ \\
\hline
\end{tabular}

* $\mathrm{RC}=$ razão de chances. 
Exposição a situações de risco para contaminação por HIV alguma vez desde 1980 e soropositividade.

\begin{tabular}{|c|c|c|c|c|c|c|}
\hline & \multicolumn{2}{|c|}{ Geral $(n=570)$} & \multicolumn{2}{|c|}{ HIV+ (n = 59) } & \multirow{2}{*}{$\begin{array}{c}\text { RC* (IC95\%) }^{*} \text { ( }=511\end{array}$} & \multirow[t]{2}{*}{$\mathbf{p}$} \\
\hline & $\mathrm{n}$ & $\%$ & $\mathrm{n}$ & $\%$ & & \\
\hline Transfusão sangüínea & 30 & 5,3 & 4 & 13,3 & $1,4(0,5-4,0)$ & 0,54 \\
\hline Relação heterossexual sem preservativo & 455 & 80,4 & 30 & 6,5 & $0,2(0,1-0,4)$ & $<0,001$ \\
\hline Relação homossexual sem preservativo & 58 & 10,3 & 23 & 39,6 & $8,7(4,4-17,0)$ & $<0,001$ \\
\hline Relação sexual com profissional de sexo & 56 & 9,8 & 11 & 19,6 & $2,4(1,2-4,9)$ & $<0,05$ \\
\hline Relação sexual por dinheiro & 28 & 4,9 & 3 & 10,7 & $1,0(0,3-3,6)$ & 1,0 \\
\hline Uso de drogas injetáveis, na vida & 13 & 2,3 & 6 & 46,2 & $8,2(2,6-25,1)$ & $<0,001$ \\
\hline Parceiro de usuário de drogas injetáveis & 39 & 6,9 & 6 & 15,4 & $1,6(0,7-4,1)$ & 0,28 \\
\hline
\end{tabular}

* $\mathrm{RC}$ = razão de chances: refere-se à comparação entre indivíduos HIV positivos e HIV negativos.

Tabela 4

Uso de substâncias psicoativas nos 30 dias prévios à entrevista e relação com soropositividade.

\begin{tabular}{|c|c|c|c|c|c|c|}
\hline \multirow[t]{2}{*}{ Droga } & \multicolumn{2}{|c|}{ Geral } & \multicolumn{2}{|c|}{$\mathrm{HIV+}$} & \multirow[t]{2}{*}{ RC (IC95\%) } & \multirow[t]{2}{*}{$p$} \\
\hline & $\mathrm{n}$ & $\%$ & $\mathrm{n}$ & $\%$ & & \\
\hline \multicolumn{7}{|l|}{ Álcool } \\
\hline Nenhuma vez & 192 & 33,7 & 27 & 14,1 & 1 & $<0,05$ \\
\hline Alguma vez & 378 & 66,3 & 32 & 8,5 & $0,57(0,32-1,01)$ & \\
\hline \multicolumn{7}{|l|}{ Maconha } \\
\hline Nenhuma vez & 530 & 93,0 & 55 & 10,4 & 1 & 0,60 \\
\hline Alguma vez & 40 & 7,0 & 4 & 10,0 & $0,96(0,28-2,96)$ & \\
\hline \multicolumn{7}{|l|}{ Cocaína inalada } \\
\hline Nenhuma vez & 548 & 96,1 & 55 & 10,0 & 1 & 0,18 \\
\hline Alguma vez & 22 & 3,9 & 4 & 18,2 & $1,99(0,55-6,56)$ & \\
\hline \multicolumn{7}{|l|}{ Calmantes } \\
\hline Nenhuma vez & 517 & 90,7 & 54 & 10,4 & 1 & 0,82 \\
\hline Alguma vez & 53 & 9,3 & 5 & 9,4 & $0,89(0,30-2,47)$ & \\
\hline \multicolumn{7}{|c|}{ Alguma droga ilícita } \\
\hline Nenhuma vez & 517 & 90,7 & 52 & 10,1 & 1 & 0,47 \\
\hline Alguma vez & 53 & 9,3 & 7 & 13,2 & $1,36(0,53-3,34)$ & \\
\hline
\end{tabular}

$\mathrm{RC}=$ razão de chances.

complexos e podem variar com a cultura do país. Um estudo realizado na Austrália discute que a maioria das pessoas testadas se encontra em baixo risco para a infecção, comparadas com o tipo de população que poderia ser atingida. Os autores sugerem que os medos, as crenças e culpas relacionados a uma doença estigmatizante e potencialmente fatal dificultam a procura pelo exame. Outro dado interessante é que muitos indivíduos procuram o exame de- vido a influências externas, como, por exemplo, a exigência do cônjuge, ou como uma "medida administrativa" para iniciar um novo relacionamento 23,24. Nesse sentido, Renzi et al. 22 descreveram que, em uma amostra de 2.603 indivíduos entre 18 e 49 anos entrevistados por telefone, $27,0 \%$ dos homens e 33,0\% das mulheres reportavam terem realizado teste antiHIV, voluntário ou não. A análise multivariada mostrou que ter múltiplos parceiros sexuais 
aumentava a chance de teste em homens (OR: 2,10; IC95\%: 1,3-3,4) e mulheres (OR: 3,03; IC95\%: 1,7-5,4). Além disso, indivíduos com idades entre 30 e 39 anos também tinham mais chance de terem sido testados em relação aos indivíduos mais jovens (OR: 3,30; IC95\%: 1,47,9) 22. Com metodologia similar, Houston et al. 25 encontraram que, entre 3.123 canadenses maiores de 15 anos, $40,0 \%$ dos homens e 30,0\% das mulheres já haviam realizado o teste antiHIV. Os principais fatores associados com testagem voluntária entre os homens foram: ter tido relação sexual com outro homem $(\mathrm{OR}=16,8)$, ter usado droga injetável $(\mathrm{OR}=5,8)$, ter tido um parceiro com alto risco $(\mathrm{OR}=2,5)$, ter 45 anos ou menos $(\mathrm{OR}=1,8)$ e ganhar menos de U\$ 30 mil por ano $(\mathrm{OR}=1,6)$. Para as mulheres, os fatores associados foram: ter tido um parceiro de alto risco $(\mathrm{OR}=3,5)$, ter menos de 45 anos $(\mathrm{OR}=$ $2,4)$, ter tido sexo com homem $(\mathrm{OR}=2,3)$ e ser solteira $(\mathrm{OR}=2,0)$.

Em nosso estudo, no que tange ao gênero, foi encontrada maior prevalência de soropositividade entre os homens, o que corrobora estudos anteriores com amostras coletadas nos mesmos locais, porém com características diferentes quanto ao uso de drogas: Pechansky \& von Diemen 14 encontraram diferenças significativas entre homens e mulheres em uma amostra de 695 indivíduos que vinham buscar testagem HIV, mas essas eram explicadas pelos comportamentos mais fortemente associados à soropositividade nos diferentes gêneros - uso e compartilhamento de drogas injetáveis pelos homens $(40,0 \%)$ e pelas mulheres $(20,0 \%)$, além de relações homossexuais mais freqüentes entre os homens $(10,0 \%)$ e ausência dessas entre as mulheres, bem como maior freqüência de relações heterossexuais entre mulheres com parceiros sexuais que faziam uso de drogas injetáveis. Em outro estudo sobre a mesma base de dados, De Boni \& Pechansky 17 não encontraram uma associação direta entre gênero e soropositividade. Entretanto, os autores mencionam, na discussão do artigo, que isso poderia ser um achado histórico na transição das razões de soroprevalência entre homens e mulheres (os dados também foram coletados entre 1995 e 1997), quando haveria um progressivo nivelamento entre as diferenças da razão homem/mulher que era encontrada previamente (maior nos homens). Esses achados não refletem a situação atual da epidemia no Brasil, já que a relação entre as taxas de soroprevalência aparece, no momento, invertida entre a população de 13 a 19 anos, com mais casos de AIDS em mulheres do que em homens. Considerando-se a razão de casos entre homens e mulheres em todas as faixas etárias, esse indicador variou de, em média, 6,5 casos entre homens para cada caso entre mulheres no período de 1980-1990 para 1.7: 1 em 2001 2. Silva-Lima et al. 26, comparando soropositividade entre 420 usuários de drogas (UDIs e não UDIs) da mesma base de dados, não encontraram diferenças entre os gêneros, apesar de identificar que os homens se expunham três vezes mais ao risco pelo uso de drogas injetáveis, enquanto que as mulheres o faziam pelas relações sexuais com parceiros UDIs potencialmente contaminados. Na verdade, pelo que se pode observar, o gênero é determinador de comportamentos mais associados à soropositividade. Isso corrobora os achados deste estudo, relatados na Tabela 2: uma maior proporção de relações heterossexuais desprotegidas e relações sexuais com UDIs entre as mulheres, e uma maior proporção de relações homossexuais desprotegidas e relações com profissionais de sexo entre os homens. Existem aqui fatores culturais importantes a serem analisados, pois estão diretamente envolvidos na prática e na percepção de risco de homens e mulheres. As mulheres têm maior dificuldade em negociar sexo seguro com seus parceiros, e isso as deixa vulneráveis para práticas sexuais de risco, seja sexo sem preservativo, seja sexo com usuários de drogas injetáveis 27,28 . Há uma associação entre um maior número de testes para HIV e relação homossexual entre os homens 19,21: homens que fazem sexo com homens e aqueles que têm relação sexual com profissional de sexo se percebem sob maior risco e procuram por testes anti-HIV com maior freqüência. Segundo nossos dados, caso eles façam o teste, terão maior chance de apresentar resultado positivo.

Em nosso estudo, embora alta quando comparada à da população brasileira em geral, a prevalência de soropositividade HIV nessa amostra -9,9\% - foi inferior à encontrada em usuários sistemáticos de drogas não injetáveis 22,6\% (von Diemen L. et al.; 2003, comunicação pessoal) - o que reforça a importância desse fator na transmissão do vírus - mas foi semelhante à encontrada em um estudo na mesma população, que incluía todos os indivíduos que procuravam o centro de testagem e aconselhamento para realizar teste anti-HIV, cuja soroprevalência geral foi de $11,9 \% 29$ - indicando que essa provavelmente é a prevalência de infecção aproximada dos sujeitos que buscam os CTAs. Há uma similaridade nos achados desses estudos, no que compete às diferenças encontradas em relação à soropositividade: encontrou-se que a idade esteve diretamente associada a uma maior soropositividade, e que a 
renda estava inversamente relacionada a esta, confirmando dados obtidos anteriormente pelo mesmo grupo de pesquisa em outras amostras 16,30. Em relação à idade, indivíduos mais velhos podem apresentar maior chance de infecção por HIV por terem se exposto a situações de risco durante mais tempo, bem como por terem sido expostos ao vírus em uma época em que havia menos informação preventiva. Entretanto, cabe ressaltar que os dados oficiais do Ministério da Saúde salientam o fato de que a incidência de HIV tem aumentado nas parcelas mais jovens da população, especialmente entre adolescentes do sexo feminino ${ }^{2}-$ e isso parece estar relacionado ao início precoce da atividade sexual de adolescentes do sexo feminino com homens mais velhos.

No que compete à renda, indivíduos de classes econômicas menos favorecidas apresentaram maior associação com soropositividade, o que corrobora diversos estudos de outras fontes, inclusive o modelo teórico proposto pelo próprio grupo de autores 5 . Apesar de não ter sido identificada uma associação entre baixa escolaridade e soropositividade neste estudo, sabe-se que, de maneira geral, indivíduos de baixa renda também têm menor nível educacional e menor acesso às informações sobre saúde, tornando-se alvos de doenças potencialmente evitáveis através de mudanças de comportamento, o que justificaria um foco especial no desenvolvimento ou adaptação de metodologia preventiva específica para esse extrato populacional.

Um achado pouco convergente com a literatura é o de que indivíduos soropositivos tiveram um uso mais freqüente de preservativos nas suas relações. Alguns autores consideram que, por se perceberem sob maior risco ou por saberem de sua condição imunológica, esses indivíduos podem vir a desenvolver uma atitude preventiva em relação à reinfecção ou à infecção de terceiros, por isso aumentando o uso de preservativos durante as relações. Kwiatkowski et al. 31 descrevem o incremento de 15,0\% para 22,0\% no uso de preservativos durante as relações sexuais, em uma amostra de 3.357 indivíduos de nove cidades americanas, com uma razão de chance maior nos indivíduos soropositivos, que receberam informação sobre AIDS, e com múltiplos parceiros, portanto confirmando a impressão de que se perceber sob maior risco - seja por ser soropositivo ou por ter sido adequadamente aconselhado - pode levar a cuidados preventivos mais adequados. Outro achado que não condiz com os conhecimentos vigentes foi sobre o consumo eventual de álcool ter sido associado com menor taxa de infecção. Esse resultado pode ter sido devido ao acaso, sem relevância clínica ou derivado de fator de confusão, já que foram realizadas apenas análises bivariadas neste estudo. No que compete ao uso de outras substâncias, os achados deste estudo confirmam que o uso não sistemático de drogas nos trinta dias prévios à coleta não foi associado à soropositividade. Entretanto, confirmando achados anteriores desse grupo de pesquisa, o relato de uso de drogas injetáveis em alguma vez na vida esteve novamente associado fortemente com soropositividade. Em estudo comparando usuários injetáveis e não injetáveis de uma amostra coletada no mesmo local, Silva-Lima et al. 26 já haviam reportado que qualquer história de injeção de drogas desde 1980 elevava o risco de infecção pelo vírus HIV em cinco vezes, quando comparado com não injeção de drogas.

Uma possível limitação do estudo, tanto em relação à generalização dos achados como a eventuais distorções na coleta de dados, é o fato de que, em função da logística específica de funcionamento de cada um dos centros de aconselhamento, a coleta de dados no centro municipal foi realizada após uma palestra de grupo para aconselhamento sobre HIV/AIDS, e, no centro estadual, os dados foram coletados antes desse procedimento. É possível que os indivíduos do centro municipal estivessem, portanto, mais informados sobre o significado de situações e comportamentos associados à soropositividade do que os indivíduos do centro estadual. Entretanto, a maioria dos dados analisados é retrospectivo, o que a princípio ficaria pouco alterado pela percepção atual do respondente.

Considerando o que foi exposto anterior mente, os autores acreditam que são necessárias intervenções focadas na prevenção da transmissão do HIV em populações de maior risco usuários de drogas injetáveis e seus parceiros, e indivíduos com baixa renda e escolaridade. Também são necessárias abordagens distintas para homens e mulheres, já que aparentemente eles apresentam práticas de risco diferentes 32. Em relação às mulheres, têm sido propostas intervenções que não apenas as informem sobre fatores de risco, mas também sejam capazes de lhes ensinar a negociar sexo seguro e abordar questões sobre auto-estima e auto-eficácia. Quanto aos homens, é essencial que sejam abordadas questões sobre relações homossexuais e uso de drogas injetáveis. 


\section{Resumo}

Este estudo descreve comportamentos de risco para HIV, obtidos através de questionário, em 570 indivíduos de Porto Alegre que não usavam drogas regularmente. A idade média foi 30,3, 51,1\% eram homens, $e$ a maioria tinha baixa renda $(59,1 \%)$. A soropositividade foi de 9,9\% (13,1\% entre homens e 6,9\% entre mulheres), associada a sexo masculino, ter mais de 30 anos e baixa renda. Mulheres reportaram mais sexo desprotegido $(86,4 \%)$ do que homens $(74,4 \%)$ e mais sexo com usuários de droga injetável (11,6\% versus 2,1\%); homens relataram mais sexo homossexual desprotegido $(18,7 \%$ versus $1,4 \%)$ e mais relações com profissionais de sexo (19,0\% versus 0,4\%). Não houve associação entre uso eventual de drogas e soropositividade. A idade associada à soropositividade confirma achados anteriores, indicando maior exposição a riscos durante a vida. O estudo confirma a pauperização da epidemia, com indivíduos pobres apresentando maior soropositividade. Homens e mulheres apresentaram diferentes comportamentos associados à soropositividade, confirmando a necessidade de prevenção específica e distinta para cada grupo.

Síndrome de Imunodeficiência Adquirida; Abuso de Drogas; Comportamento de Risco; Testes Sorológicos

\section{Colaboradores}

F. Pechansky coordenou todo o projeto de pesquisa e escreveu os rascunhos do texto final. L. von Diemen gerenciou o manejo dos dados e escreveu os rascunhos do texto final. F. Kessler gerenciou a coleta dos dados e escreveu os rascunhos do texto final. R. De Boni organizou as tabelas e referências bibliográficas. H. Surrat e J. Inciardi supervisionaram a adaptação da técnica de coleta originária dos Estados Unidos e orientaram a discussão, bem como anexaram referências bibliográficas ao texto final.

\section{Agradecimentos}

Os autores agradecem à Dra. Adriana Carvalhal, à estatística Vânia Naomi Hirakata e à acadêmica Vanessa Krebs Genro pelo auxílio na análise dos dados e na confecção do primeiro manuscrito deste artigo

\section{Referências}

1. Ministério da Saúde. Boletim epidemiológico AIDS 2003. Dados e pesquisas em DST e AIDS - Dados de AIDS. http://www.aids.gov.br/final/dados/ aids.htm (acessado em 27/Abr/2004).

2. Ministério da Saúde. Boletim epidemiológico AIDS 2003. Dados e pesquisas em DST e AIDS. Dados de AIDS Tabela VII - casos de AIDS em indivíduos do sexo masculino com 13 anos de idade ou mais, segundo categoria de exposição hierarquizada e ano de diagnóstico. Brasil, 1980 a 2003. http:// www.aids.gov.br/final/dados/dados_coletiva/tab ela7.htm (acessado em 27/Abr/2004).

3. Ministério da Saúde. Boletim epidemiológico AIDS 2003. Dados e pesquisas em DST e AIDS. Dados de AIDS Tabela VIII - Casos de AIDS em indivíduos do sexo feminino com 13 anos de idade ou mais, segundo categoria de exposição hierarquizada e ano de diagnóstico. Brasil, 1983 a 2003. http:// www.aids.gov.br/final/dados/dados_coletiva/tab ela8.htm (acessado em 27/Abr/2004).

4. Parker R, Camargo Jr. KR. Pobreza e HIV/AIDS: aspectos antropológicos e sociológicos. Cad Saúde Pública 2000; 16 Suppl 1:89-102.

5. Pechansky F. Modelo teórico de exposição a risco para transmissão do vírus HIV em usuários de drogas. Rev Bras Psiquiatr 2001; 23:39-45.

6. Pechansky F. Um estudo sobre situações de risco para contaminação pelo vírus HIV em usuários de drogas da cidade de Porto Alegre [Tese de Doutorado]. Porto Alegre: Curso de Pós-graduação em Clínica Médica, Universidade Federal do Rio Grande do Sul; 1998.

7. Sherman SG, Latkin CA. Intimate relationship characteristics associated with condom use among drug users and their sex partners: a multilevel analysis. Drug Alcohol Depend 2001; 64:97-104.

8. McCoy HV, Inciardi JA. Women and AIDS: social determinants of sex-related activities. Women Health 1993; 20:69-86.

9. Solomon L, Moore J, Gleghorn A, Astemborski J, Vlahov D. HIV testing behaviors in a population of inner-city women at high risk for HIV infection. J Acquir Immune Defic Syndr Hum Retrovirol 1996; 13:267-72.

10. Mansson SA. Psycho-social aspects of HIV testing - the Swedish case. AIDS Care 1990; 1:5-12.

11. Siegel K, Levine M, Brooks C, Kern R. The motives of gay men for taking or not taking the HIV antibody test. Soc Probl 1989; 36:368-83.

12. Knussen C, Flowers P, Church S. The intentions of gay men in taking an HIV test. Cult Health Sex 2004; 6:45-59.

13. Pechansky F, Soibelman M, Kohlrausch E. Assessment of risk situations for HIV transmission among drug abusers in Porto Alegre, Brazil. J Drug Issues 1997; 27:147-54.

14. Pechansky F, von Diemen L. Homens e mulheres usuários de drogas: semelhanças e diferenças na exposição ao vírus HIV em Porto Alegre. Revista da Associação Brasileira de Estudos do Álcool e outras Drogas 1998; 1/2:15-25.

15. Pechansky F, Inciardi J, Surratt H, Silva-Lima AF, Kessler F, Soibelman M, et al. Um estudo exploratório sobre as características de usuários de 
drogas injetáveis que buscam atendimento em Porto Alegre. Rev Bras Psiquiatr 2000; 22:164-71.

16. Pechansky F, von Diemen L, Genro V. Presença de situações de risco para a transmissão do HIV em usuários de drogas não injetáveis. Rev Psiquiatr Clín (São Paulo) 2001; 28:157-9.

17. De Boni R, Pechansky F. Age and gender as risk factors for the transmission of HIV in a sample of drug users of Porto Alegre, Brazil. Rev Bras Psiquiatr 2002; 24:137-40.

18. Pechansky F, Metzger D, Hirakata V. Adaptation and validation of a questionnaire about risk behaviors for AIDS among drug users. Rev Bras Psiquiatr 2002; 24:130-6.

19. Murphy D, Mitchell R, Vermund SH, Futterman D, Adolescent Medicine HIV/AIDS Research Network. Factors associated with HIV testing among HIV-positive and HIV-negative high risk adolescentes: the REACH Study. Pediatrics 2002; 110:e36.

20. Miller KS, Hennessy M, Wendell DA, Webber MP, Schoenbaum EF. Behavioral risks for HIV infection associated with HIV testing decisions. AIDS Educ Prev 1996; 8:394-402.

21. Fernyak SE, Page-Shafer K, Kellogg TA, McFarland W, Katz MH. Risk behaviours and HIV incidence among reapeat testers at publicly funded HIV testing sites in San Francisco. J Acquir Immune Defic Syndr 2002; 31:63-70.

22. Renzi C, Zantedeschi E, Signorelli C, Osborn JF. Factors associated with HIV testing: results from an Italian General Population Survey. Prev Med 2001; 32:40-8.

23. Lupton D, McCarthy S, Chapman S. Doing the right thing: the symbolic meanings and experiences of having an antibody test. Soc Sci Med 1995; 41:173-80.

24. Lupton D, McCarthy S, Chapman S. "Panic bodies" discourses on risk and HIV antibody testing. Sociol Health Illn 1995; 17:89-108.
25. Houston S, Archibald CP, Strike C, Sutherland D. Factors associated with HIV testing among Canadians: results of a population-based survey. Int J STD AIDS 1998; 9:341-6.

26. Silva-Lima AFB, Pechansky F, Genro VK. Soropositividade para HIV entre usuários de drogas em Porto Alegre: uma comparação entre usuários e não-usuários de drogas injetáveis. J Bras Psiquiatr 2002; 51:323-6.

27. Latka M, Gollub E, French P, Stein Z. Male-condom and female-condom use among women after couseling in a risk-reduction hierarchy for STD prevention. Sex Transm Dis 2000; 27:431-7.

28. Gollub EL, Brown EL, Savouillan M, Waterlot J, Coruble G. A community-based safer-sex intervention for women:results of a pilot study in southeastern France. Cult Health Sex 2002; 4:21-41.

29. Barcellos NT, Fuchs SC, Fuchs FD. Prevalence of and risk factors for HIV infection in individuals testing for HIV at counseling centers in Brazil. Sex Transm Dis 2003; 30:166-73.

30. Pechansky F, von Diemen L, Kessler F, Hirakata V, Metzger D, Woody G. Preliminary Estimates of human immunodeficiency virus prevalence and incidence among cocaine abusers of Porto Alegre, Brazil. J Urban Health 2003; 80:115-26.

31. Kwiatkowski CF, Stober DR, Booth RE, Zhang Y. Predictors of increased condom use following HIV intervention with heterosexually active drug users. Drug Alcohol Depend 1999; 54:57-62.

32. Apanovich A, McCarthy D, Salovey P. Using message framing to motivate HIV testing among lowincome, ethnic minority women. Health Psychol $2003 ; 22: 60-7$.

Recebido em 06/Out/2003

Versão final reapresentada em 24/Mai/2004 Aprovado em 01/Set/2004 